\title{
Outcome of Pediatric Cataract Surgery in Patients Who Have Undergone Bone Marrow Transplantation
}

\author{
Ariel Chen ${ }^{1}$, Kimberly G Yen² \\ ${ }^{1}$ Department of Ophthalmology, Baylor College of Medicine, Houston, USA \\ ${ }^{2}$ Department of Ophthalmology and Pediatrics, Texas Children's Hospital, Houston, USA \\ Email:kgyen@texaschildrens.org
}

How to cite this paper: Chen, A. and Yen, K.G. (2018) Outcome of Pediatric Cataract Surgery in Patients Who Have Undergone Bone Marrow Transplantation. Open Journal of Ophthalmology, 8, 54-63.

https://doi.org/10.4236/ojoph.2018.81008

Received: January 25, 2018

Accepted: February 23, 2018

Published: February 26, 2018

Copyright (c) 2018 by authors and Scientific Research Publishing Inc. This work is licensed under the Creative Commons Attribution International License (CC BY 4.0).

http://creativecommons.org/licenses/by/4.0/

\section{(c) (7) Open Access}

\begin{abstract}
Purpose: Bone marrow transplantation (BMT) and pre-treatment conditioning increases the risk of developing pediatric cataracts. We present the outcome of cataract surgery in children who have had BMT. Methods: We conducted a retrospective chart study with 15 BMT patients (28 eyes) who underwent cataract extraction between 2002 and 2012. Outcome measures include change in best corrected visual acuity (BCVA) and complications. Results: 7 (47\%) patients had acute lymphoid leukemia, 3 (20\%) had acute myeloid leukemia, 2 (13\%) had myelodysplastic syndrome, 1 (7\%) had Fanconi anemia, 1 (7\%) had juvenile myelomonocytic leukemia, and 1 (7\%) had adrenoleukodystrophy. Patients received BMT at a mean age of $3.9 \pm 1.6$ years. 12 (80\%) patients received total body irradiation (TBI) and 3 of these 12 received cranial irradiation in addition to TBI; one (7\%) received only cranial irradiation. Total body irradiation included head and eye exposure. Mean age of cataract surgery was $9.1 \pm 2.3$ years; mean follow-up was $55.9 \pm 45.1$ months. All cataracts were of posterior subcapsular subtype. Mean BCVA improved from $0.7 \pm 0.4 \log$ MAR to $0.3 \pm 0.5 \log$ MAR $(p<0.001) .23 / 28$ eyes $(80 \%)$ had cataract extraction with intraocular lens placement; $5 / 28(20 \%)$ of the eyes had cataract extraction with primary posterior capsulotomy and anterior vitrectomy (PC/AVx). 23/23 (100\%) of the eyes without primary PC/AVx developed PCO an average of $2.3 \pm 6.9$ months after surgery. No eyes with primary PC/AVx eyes developed PCO. Conclusions: Children with history of BMT have a predisposition of developing posterior subcapsular cataracts and have a high rate of visually significant PCO if the posterior capsule is left intact at the time of cataract surgery.
\end{abstract}

\section{Keywords}

Pediatric Cataract, Pediatric Cataract Surgery, Bone Marrow Transplant 


\section{Introduction}

Bone marrow transplantation (BMT) with pre-treatment conditioning is an established treatment for childhood leukemia, myelodysplastic syndrome and other hereditary and metabolic hematologic disorders. While BMT has increased life-expectancy for children with hematologic disorders, this life-saving intervention has a number of sequelae including cataract formation. Common conditioning pre-treatments for BMT include irradiation, corticosteroid treatment, and chemotherapy, each of which have been independently observed to be associated with increased cataract formation [1] [2] [3] [4] [5]. A number of studies have found that total body irradiation (TBI), compared to chemotherapy and corticosteroids, is likely the most significant factor for developing cataracts in patients who received BMT [6]-[11].

Although pediatric cataracts occur frequently in patients who have had BMT, there is limited data in the literature regarding the surgical outcome of cataracts in these patients. This study aims to characterize the cataracts that develop in pediatric bone marrow transplant patients and describe the complications and visual outcomes of cataract surgery in these patients.

\section{Materials and Methods}

Prior to initiating this study, institutional review board approval was obtained from the Baylor College of Medicine. A comprehensive database search of our electronic medical record was performed to identify all patients under the age of 18 with history of BMT who had cataract surgery between September 25, 2002 and December 4, 2012. Patients were excluded if BMT was received at an outside institution, or if the patient had less than 1 month of follow-up after cataract surgery.

For patients unable to cooperate in clinic, intraocular lens calculations were performed in the operating room using immersion A-scan ultrasonography for axial length measurements and keratometry was obtained using a handheld keratometer. Cataract surgery was performed using standard technique [12] [13]. Briefly, in cases in which the posterior capsule was left intact, a temporal clear corneal incision was made using a keratome and a continuous curvilinear capsulorrhexis was performed with utrata forceps; aspiration of the lens was accomplished using an automated irrigation/aspiration handpiece with the Accurus system (Alcon Laboratories). In patients in which a primary posterior capsulotomy and anterior vitrectomy was planned, the anterior capsulotomy and lens aspiration were performed using a mechanical vitrectomy handpiece using bimanual technique. Primary posterior capsulotomy and anterior vitrectomy through the pars plana approach was then performed in a standard fashion after placement of the intraocular lens [14].

All patients received a single piece, foldable acrylic IOL (Acrysof, SN60AT). The optic and haptics were placed in the capsular bag. All patients were treated postoperatively with prednisolone acetate $1 \%$ eye drops every 2 hours for the 
first week followed by tapering over the next 4 weeks. Topical moxifloxacin was given 4 times a day for 1 week postoperatively.

Visually significant posterior capsular opacification (PCO) or visual axis opacification (VAO) was defined as PCO or VAO that disrupted retinoscopy, caused decreased near or distance vision less than 20/40, or was associated with symptomatic complaints from the patient. If patients developed visually significant posterior capsular opacification (PCO) and were cooperative at the slit lamp, they were treated with Nd:YAG laser. Patients who were not candidates for Nd:YAG laser due to age or cooperation received surgical posterior capsulotomy with planned anterior vitrectomy.

BMT parameters reviewed were diagnosis, age of BMT, type of BMT donor, conditioning regimen, total body irradiation received, cranial irradiation received, and presence of graft versus host disease (GVHD). Subject parameters reviewed included sex; age; type of cataract; preoperative, postoperative, and most recent visual acuities; presence of amblyopia; length of follow-up; development of posterior capsular opacification; and need for YAG laser treatment. Snellen visual acuities were converted to logarithm of minimal angel of resolution values for statistical analysis. Descriptive statistics and the 2-tailed paired $t$ test from Microsoft Excel 2010 were used to determine significance. Significance was defined by a $\mathrm{P}$ value of 0.05 or less.

\section{Results}

A total of 31 eyes in 18 patients who had cataract surgery after BMT were identified. Two patients were excluded because they received BMT at outside institutions and one patient was excluded due to not returning for any post-operative visits. Therefore, twenty-eight eyes in 15 patients met the criteria for inclusion. Six of the patients were female and 9 were male. The patients received BMT between April 1, 1991 and October 8, 2009. Seven patients (47\%) had acute lymphoid leukemia, 3 patients (20\%) had acute myeloid leukemia, 2 patients (13\%) had myelodysplastic syndrome, 1 patient (7\%) had Fanconi anemia, 1 patient (7\%) had juvenile myelomonocytic leukemia, and 1 (7\%) had adrenoleukodystrophy (Table 1).

Patients received BMT and conditioning chemotherapy at a mean age of $3.9 \pm$ 1.6 years (range, $0.5-6.4$ years). Nine (60\%) patients received TBI only and 3 (20\%) patients received cranial irradiation in addition to TBI; one (7\%) received only cranial irradiation and 2 patients (13.3\%) received neither TBI nor cranial irradiation. TBI included head and eye exposure without shielding of the eyes. Of the patients who did not receive TBI or cranial irradiation, one received systemic prednisone treatment for graft versus host disease (GVHD) and the other was treated with topical corticosteroids for skin hypopigmentation. A total of eight of 15 patients (53\%) developed graft versus host disease (GVHD); five of these patients were treated with systemic prednisone. Other immunosuppressive therapies used include tacrolimus, cyclosporine, rituximab and infliximab. One 
Table 1. Sociodemographic and clinical characteristics of patients.

\begin{tabular}{|c|c|}
\hline Sex, n (\%) & \\
\hline Male & $9(60)$ \\
\hline Female & $6(40)$ \\
\hline \multicolumn{2}{|l|}{ Ethnicity, n (\%) } \\
\hline Caucasian & $7(47)$ \\
\hline Hispanic & $7(47)$ \\
\hline African American & $1(7)$ \\
\hline \multicolumn{2}{|l|}{ Eye, n (\%) } \\
\hline$O D$ & $15(54)$ \\
\hline OS & $13(46)$ \\
\hline \multicolumn{2}{|l|}{ Hematologic disorder, $\mathrm{n}(\%)$} \\
\hline Acute lymphoid leukemia & $7(47)$ \\
\hline Acute myeloid leukemia & $3(20)$ \\
\hline Meylodysplastic syndrome & $2(13)$ \\
\hline Fanconi anemia & $1(7)$ \\
\hline Juvenile myelomonocytic leukemia & $1(7)$ \\
\hline Adrenoleukodystrophy & $1(7)$ \\
\hline Mean age of BMT, years (SD) & $3.9(1.6)$ \\
\hline Total body irradiation, $\mathbf{n}(\%)$ & $9(60)$ \\
\hline Cranial irradiation, $\mathrm{n}(\%)$ & $4(27)$ \\
\hline Mean age of cataract surgery, years (SD) & $9.1(2.3)$ \\
\hline Mean logMAR pre-op (SD) & $0.7(0.4)$ \\
\hline Mean logMAR most recent (SD) & $0.3(0.5)$ \\
\hline Mean follow-up, months (SD) & $55.9(45.1)$ \\
\hline
\end{tabular}

patient was treated for severe keratoconjunctivitis sicca and a corneal ulcer that had developed due to complications from GVHD. Seven (47\%) patients were Caucasian, 7 (47\%) were Hispanic, and 1 (7\%) was African American.

Mean time from bone marrow transplantation to cataract development was an average of $3.5 \pm 1.8$ years (range, 1.4 - 11.8 years). Mean age of diagnosis of cataracts was $7.4 \pm 2.0$ years (range, $4.6-14.9$ years) and mean age at surgery was $9.1 \pm 2.3$ years (range, $6.0-15.4$ years). Mean follow-up was $55.9 \pm 45.1$ months (range, 1.0 - 131.3 months) (Table 2).

All cataracts were of the posterior subcapsular subtype. Mean best corrected visual acuity (BCVA) improved from $0.7 \pm 0.4 \log$ MAR (Snellen 20/100) pre-op to $0.3 \pm 0.5 \operatorname{logMAR}$ (Snellen $20 / 40)$ at most recent visit $(p<0.001)$. Twenty-four of 28 eyes $(85.7 \%)$ had improved visual acuity with Snellen BCVA of $20 / 40$ or better at the most recent visit. Two of the eyes that did not improve belonged to a patient with bilateral optic atrophy due to leukemic infiltration. The other two eyes belonged to a patient with severe keratoconjunctivitis sicca due to GVHD; this patient also had a corneal scar in one eye which developed after a microbial keratitis. 
Table 2. Cataract development in children with history of bone marrow transplantation.

\begin{tabular}{|c|c|c|c|c|c|c|c|}
\hline Patient & $\begin{array}{c}\text { Diagnosis } \\
\text { (Sex/Ethnicity) }\end{array}$ & $\begin{array}{c}\text { BMT Age } \\
(y r)\end{array}$ & Eye & $\begin{array}{l}\text { CE Age } \\
(\mathrm{yr})\end{array}$ & $\begin{array}{l}\text { Follow-up } \\
\text { (mo) }\end{array}$ & $\begin{array}{l}\text { Pre-op } \\
\text { BCVA }\end{array}$ & $\begin{array}{c}\text { Most recent } \\
\text { BCVA }\end{array}$ \\
\hline \multirow[t]{2}{*}{ A } & $\operatorname{ALD}($ male/C) & 4.1 & 1 & 8.5 & 86.3 & $20 / 80$ & $20 / 20$ \\
\hline & & & 2 & 8.6 & 86.1 & $20 / 60$ & $20 / 25$ \\
\hline \multirow[t]{2}{*}{ B } & ALL (male/C) & 2.6 & 3 & 6.0 & 103.6 & $20 / 30$ & $20 / 20$ \\
\hline & & & 4 & 6.0 & 103.3 & $20 / 40$ & $20 / 20$ \\
\hline $\mathrm{C}$ & ALL (male/C) & 3.1 & 5 & 15.4 & 21.3 & $20 / 50$ & $20 / 20$ \\
\hline \multirow[t]{2}{*}{$\mathrm{D}$} & ALL (female/H) & 3.5 & 6 & 7.1 & 127.1 & $20 / 80$ & $20 / 20$ \\
\hline & & & 7 & 7.2 & 125.7 & $20 / 80$ & $20 / 15$ \\
\hline \multirow[t]{2}{*}{$\mathrm{E}$} & ALL (female/H) & 4.8 & 8 & 9.9 & 59.3 & $20 / 40$ & $20 / 30$ \\
\hline & & & 9 & 10.0 & 58.6 & $20 / 50$ & $20 / 30$ \\
\hline $\mathrm{F}$ & ALL (female/H) & 5.4 & 10 & 8.0 & 67.4 & $20 / 250$ & $20 / 60$ \\
\hline \multirow[t]{2}{*}{ G } & ALL (female/G) & 5.8 & 11 & 11.7 & 68.4 & $20 / 200$ & $20 / 60$ \\
\hline & & & 12 & 11.4 & 71.7 & $20 / 100$ & $20 / 20$ \\
\hline \multirow[t]{2}{*}{$\mathrm{H}$} & ALL (female/H) & 6.4 & 13 & 11.0 & 6.9 & $20 / 80$ & $20 / 40$ \\
\hline & & & 14 & 11.0 & 6.6 & $20 / 60$ & $20 / 40$ \\
\hline \multirow[t]{2}{*}{ I } & AML (male/C) & 3.3 & 15 & 13.0 & 1.2 & $20 / 150$ & $20 / 30$ \\
\hline & & & 16 & 13.0 & 1.0 & $20 / 300$ & $20 / 40$ \\
\hline \multirow[t]{2}{*}{$\mathrm{J}$} & AML (male/AA) & 3.6 & 17 & 7.9 & 107.8 & $2 \mathrm{ft} 200$ & $\mathrm{CF} 1 \mathrm{ft}$ \\
\hline & & & 18 & 7.9 & 107.1 & $2 \mathrm{ft} 200$ & $\mathrm{CF} 1 \mathrm{ft}$ \\
\hline \multirow[t]{2}{*}{ K } & AML (male/C) & 3.9 & 19 & 7.9 & 11.9 & $20 / 60$ & $20 / 30$ \\
\hline & & & 20 & 7.7 & 14.0 & $20 / 70$ & $20 / 30$ \\
\hline \multirow[t]{2}{*}{$\mathrm{L}$} & Fanconi (female/H) & 6.3 & 21 & 9.5 & 24.8 & $20 / 150$ & $20 / 30$ \\
\hline & & & 22 & 9.5 & 24.5 & $20 / 70$ & $20 / 30$ \\
\hline \multirow[t]{2}{*}{ M } & JML (male/C) & 0.5 & 23 & 9.4 & 5.3 & $20 / 80$ & $20 / 80$ \\
\hline & & & 24 & 9.4 & 4.6 & $20 / 40$ & $20 / 50$ \\
\hline \multirow[t]{2}{*}{$\mathrm{N}$} & MDS (male/H) & 2.0 & 23 & 7.0 & 130.1 & $20 / 50$ & $20 / 25$ \\
\hline & & & 26 & 6.9 & 131.3 & $20 / 60$ & $20 / 30$ \\
\hline \multirow[t]{2}{*}{$\mathrm{O}$} & MDS (female/C) & 4.1 & 27 & 7.1 & 23.1 & $20 / 50$ & $20 / 30$ \\
\hline & & & 28 & 7.1 & 22.9 & $20 / 50$ & $20 / 30$ \\
\hline
\end{tabular}

a. AA, African American; ALD, adrenoleukodystrophy; ALL, acute lymphoid leukemia; AML, acute myeloid leukemia; C, Caucasian; BCVA, best corrected visual acuity; H, Hispanic; JML, juvenile myelomonocytic leukemia; MDS, myelodysplastic syndrome.

Twenty-three of 28 eyes (80\%) had cataract extraction with intraocular lens placement in the bag; 5/28 (20\%) of the eyes had cataract extraction with intraocular lens placement in the bag with primary posterior capsulotomy and anterior vitrectomy $(\mathrm{PC} / \mathrm{AVx})$. There were no surgical complications.

None of the eyes which received primary PC/AVx developed subsequent visual axis opacification (VAO). Twenty-one of the 23 eyes (91\%) that did not have 
primary PC/AVx were noted to have some posterior capsular opacification (PCO) intraoperatively with inability to completely polish the capsule safely at the time of surgery. Eighteen of the $23(78 \%)$ of the eyes that did not have primary PC/AVx were diagnosed with visually significant PCO an average $0.7 \pm 0.9$ months (range, 0.03 - 3.2 months) after cataract surgery. The mean age at time of surgery of the 18 patients who were diagnosed with PCO was $9.4 \pm 2.6$ years (range, 5.9 - 15.2 years). Of these 18 eyes, 16 received Nd:YAG laser treatment a mean of $13.4 \pm 31.4$ months (range, 0.6 - 131.0 months) after cataract surgery. The two remaining eyes with visually significant PCO were lost to follow-up.

Irradiation dosage was available in 7/12 patients who received TBI; of these 7 patients, 6/7 received 1200 to $1400 \mathrm{~Gy}$. These six of these patients developed visually significant PCO an average of $0.3 \pm 0.4$ months (range, $0.03-1.20$ months) after surgery. The remaining patient had received $450 \mathrm{~Gy}$ and did not develop PCO until 24 months after cataract surgery. All three of the patients who did not have TBI developed visually significant PCO an average 1.3 months after surgery. One patient who had received TBI had recurrent visually significant PCO bilaterally and had repeat Nd:YAG laser 54.6 months after the first treatment. This patient had 20/20 vision in both eyes at most recent visit, with total follow-up time of 103.6 months since cataract extraction.

Other associated ocular conditions noted were myelinated nerve fibers in one eye, bilateral optic atrophy in one patient, and keratoconjuntivitissicca with 2 patients. As described above, one of the patients with keratoconjunctivitis sicca also had a corneal scar from a treated microbial keratitis. One patient had an exotropia which was corrected with surgery.

\section{Discussion}

We found that patients with cataracts which develop after BMT and conditioning treatment have a predisposition to develop posterior subcapsular type of cataracts. Other studies have also found that patients with a history of BMT have a propensity to develop cataracts of the posterior subcapsular type [7] [9] [11]. In previous studies, it has been found that BMT patients typically developed cataracts within 4 years of transplantation [6]-[11]. This is consistent with our population in which the patients developed cataracts an average of 41.6 months (3.5 years) after BMT.

TBI has been established by multiple studies to be a strong factor in the development of cataracts for patients who received BMT [6]-[11]. Fife et al. found that cranial irradiation was also a risk factor for cataract surgery after BMT [15] however other studies found no relationship between the use of cranial irradiation and the need for cataract surgery [8] [9] [16]. While steroids have been attributed to development of cataracts [2] [5], Calissendorff et al. and Holmstrom et al. were unable to conclude a relationship between steroid use associated with BMT and cataract development [6] [9]. It is likely that the development of cataracts in patients after BMT is multifactorial, as many of these patients are ex- 
posed to a variety of treatments including TBI, cranial irradiation, and systemic steroids. This is further supported by the fact that, in our series, there were two patients who did not receive either TBI or cranial irradiation.

The patients in our study had improvement in visual acuity after cataract extraction from an average Snellen BCVA 20/100 pre-operatively to 20/40 at the most recent visit. Other studies examining cataract extraction after BMT also observed improvement in BCVA after surgery [7] [8]. The two patients who had vision worse than $20 / 40$ had ocular comorbidities. One patient had bilateral optic atrophy and had visual acuity of count fingers in both eyes. The other patient had a corneal scar in the right eye and severe keratoconjunctivitis sicca due to graft versus host disease.

The high rate of visually significant PCO after cataract surgery in our patients is comparable to other studies examining patients with cataracts after BMT. Calissendorff and Bolme and Frisk, et al. showed that the majority of their patients who had cataract extractions after BMT needed Nd:YAG laser capsulotomy within 3 years of surgery and that the patients were able to achieve good visual acuity and outcome after the laser treatment [7] [8]. In Frisk, et al., of the 10 eyes that received cataract extractions and intraocular lens implants, 6 eyes needed YAG laser a median of 1.5 years after cataract extraction [8]. In Calissendorff and Bolme, 28 eyes received surgery with the majority requiring YAG laser within 2 years after surgery; however, the number of patients and time period in which the PCO developed was not specified [7]. The authors did note that cleaning the capsule intraoperatively was, in most cases, impossible with risk of causing posterior capsular breakage [7]. In our study, $78 \%$ of our patients with an intact posterior capsule developed visually significant PCO within the study time period. Although irradiation dosage was not available for all patients, in the patients for which the data was available, those with higher dosage developed PCO sooner. We also found that 91\% (21/23) of the eyes with posterior capsule left intact were found to have PCO intraoperatively with inability to completely polish the capsule completely without risk of damaging the posterior capsule. The opacification of the capsule in these patients appeared to be integrated within the capsule, perhaps in the form of capsular fibrosis, although histologic examination of the capsule was not performed and would likely be difficult to complete.

Many studies have examined rates of PCO development in children with congenital, developmental, and traumatic cataracts who had cataract extraction with IOL placement without primary PC/AVx. The PCO rates in these studies have ranged from less than 45\% [17] [18] [19] [20] to over 80\% [21] [22] [23] [24]. Jensen et al. examined rates of PCO for posterior subcapsular versus cortical cataracts in children and did not find a statistically significant difference between these two subtypes. $18 \mathrm{~A}$ risk factor associated with higher rates of PCO is younger age at time of cataract surgery [18] [19] [25] [26]. However, the average age at time of surgery for our patients who had PCO was 9.3 years, and the higher rates of PCO in other studies were observed in children younger than 4 
years old in Stager et al. and younger than 6 years old in Jensen et al. [18] [25]. Thus, we feel that our high rate of PCO is not related to the age of our patients. Although the exact mechanism of developing the PCO is not clear, we hypothesize that the TBI and other conditioning treatments may induce capsular fibrosis, causing the PCO to be integrated with the capsule, preventing the usual polishing techniques from being effective without damaging the posterior capsule. Further studies would be needed to confirm our observations.

It is worthwhile to note that of the 5 patients who had primary PC/Avx, none developed VAO in the study time period. In patients who would not be cooperative for a Nd:Yag laser, primary $\mathrm{PC} / \mathrm{Avx}$ could therefore save the patient a second intraocular procedure soon after the first. In older, cooperative patients, however, Nd:YAG laser treatment easily corrected PCO with good visual outcomes; counseling parents and patient regarding the potential need for Nd:YAG laser soon after surgery, would be appropriate in this patient population. Recurrence of PCO, which has been reported in the pediatric population [27], appears low in these patients. Only one patient required a second treatment and this patient achieved a good outcome.

Our study was limited by its retrospective nature and the small sample size as well as variable follow-up times, and lack of a control group. Ideally, treatment outcomes and complications should be assessed over many years. Irradiation dosage for TBI and length of steroid treatment would be useful to determine if there is a relationship between PCO development and these treatments. However, this data was not available for all patients due to older BMT records not being available for many of the patients.

\section{Conclusion}

Pediatric patients with history of BMT and pre-conditioning treatments are more likely to have cataracts of the posterior subcapsular cataract type; surgical treatment of these cataracts is associated with few complications and good visual outcomes. The rate of development of visually significantly PCO is high in this patient population with many patients having changes that appeared integrated with the posterior capsule and which cannot be polished intraoperatively. Although a primary posterior capsulotomy with anterior vitrectomy is effective in reducing the rate of developing visual axis opacification, Nd:YAG laser is an effective treatment for these patients and the posterior capsule can be left intact without consequence if the patient can be cooperative for this procedure.

\section{Acknowledgements}

This work was supported in part by an unrestricted grant from Research to Prevent Blindness.

\section{References}

[1] Merriam, G.R. and Focht, E.F. (1957) A Clinical Study of Radiation Cataracts and 
the Relationship to Dose. American Journal of Roentgenology, 77, 759-785.

[2] Black, R.L., Oglesby, R.B., Von Sallmann, L. and Bunim, J.J. (1960) Posterior Subcapsular Cataracts Induced by Corticosteroids in Patients with Rheumatoid Arthritis. The Journal of the American Medical Association, 174, 166-171. https://doi.org/10.1001/jama.1960.63030020005014

[3] Vizel, M. and Oster, M.W. (1982) Ocular Side Effects of Cancer Chemotherapy. Cancer, 49, 1999-2002. https://doi.org/10.1002/1097-0142(19820515)49:10<1999::AID-CNCR2820491009> 3.0.CO;2-B

[4] Fraunfelder, F.T. and Meyer, S.M. (1983) Ocular Toxicity of Antineoplastic Agents. Ophthalmology, 90, 1-3. https://doi.org/10.1016/S0161-6420(83)34600-5

[5] Urban, R.C. and Cotlier, E. (1986) Corticosteroid-Induced Cataracts. Survey of Ophthalmology, 31, 102-110. https://doi.org/10.1016/0039-6257(86)90077-9

[6] Calissendorff, B., Bolme, P., El Azazi, M. (1991) The Development of Cataract in Children as a Late Side-Effect of Bone Marrow Transplantation. Bone Marrow Transplant, 7, 427-429.

[7] Calissendorff, B. and Bolme, P. (1993) Cataract Development and Outcome of Surgery in Bone Marrow Transplanted Children. British Journal of Ophthalmology, 77, 36-38. https://doi.org/10.1136/bjo.77.1.36

[8] Frisk, P., Hagberg, H., Mandahl, A., Soderberg, P. and Lonnerholm, G. (2000) Cataracts after Autologous Bone Marrow Transplantation in Children. Acta Paediatr, 89, 814-819. https://doi.org/10.1111/j.1651-2227.2000.tb00390.x

[9] Holmström, G., Borgström, B. and Calissendorff, B. (2002) Cataract Formation after Bone Marrow Transplantation: Relation to Conditioning Regimen. Acta Ophthalmologica Scandinavica, 80, 211-215. https://doi.org/10.1034/j.1600-0420.2002.800217.x

[10] Lappi, M., Rajantie, J. and Uusitalo, R.J. (1990) Irradiation Cataract in Children after Bone Marrow Transplantation. Graefe's Archive for Clinical and Experimental Ophthalmology, 228, 218-221. https://doi.org/10.1007/BF00920023

[11] Frisk, P., Hagberg, H., Mandahl, A., Söderberg, P. and Lönnerholm, G. (2002) Cataract in Children after Autologous Bone Marrow Transplantation. A Common, But Curable Complication. Läkartidningen, 99, 1444-1447.

[12] Wilson, M.E., Trivedi, R.H. and Pandey, S.K. (2005) Pediatric Cataract Surgery: Techniques, Complications, and Management. Lippincott Williams \& Wilkins, Philadelphia.

[13] Forbes, B.J. and Guo, S. (2006) Update on the Surgical Management of Pediatric Cataracts. Journal of Pediatric Ophthalmology and Strabismus, 43, 143-151.

[14] Wilson, M.E., Saunders, R.A., Roberts, E.L. and Apple, D.J. (1996) Mechanized Anterior Capsulectomy as an Alternative to Manual Capsulorhexis in Children undergoing Intraocular Lens Implantation. Journal of Pediatric Ophthalmology \& Strabismus, 33, 237-240.

[15] Fife, K., Milan, S., Westbrook, K., Powles, R. and Tait, D. (1994) Risk Factors for Requiring Cataract Surgery Following Total Body Irradiation. Radiotherapy \& Oncology, 33, 93-98. https://doi.org/10.1016/0167-8140(94)90061-2

[16] Benyunes, M.C., Sullivan, K.M., Deeg, H.J., Motomi, M., Meyer, W., Fisher, L., et al. (1995) Cataracts after Bone Marrow Transplantation: Long Term Follow-Up of Adults Treated with Fractionated Total Body Irradiation. International Journal of Radiation Oncology, Biology, Physics, 32, 661-670.

https://doi.org/10.1016/0360-3016(94)00392-X 
[17] Basti, S., Ravishankar, U. and Gupta, S. (1996) Results of a Prospective Evaluation of Three Methods of Management of Pediatric Cataract. Ophthalmology, 103, 713-720. https://doi.org/10.1016/S0161-6420(96)30624-6

[18] Jensen, A.A., Basti, S., Greenwald, M.J. and Mets, M.B. (2002) When May the Posterior Capsule Be Preserved in Pediatric Intraocular Lens Surgery? Ophthalmology, 109, 324-327. https://doi.org/10.1016/S0161-6420(01)00950-2

[19] Hosal, B.M. and Biglan, A.W. (2002) Risk Factors for Secondary Membrane Formation after Removal of Pediatric Cataract. Journal of Cataract \& Refractive Surgery, 28, 302-309. https://doi.org/10.1016/S0886-3350(01)01028-8

[20] Zwaan, J., Mullaney, P.B., Awad, A., Al-Mesfer, S. and Wheeler, D.T. (1998) Pediatric Intraocular Lens Implantation: Surgical Results and Complications in More than 300 Patients. Ophthalmology, 105, 112-118. https://doi.org/10.1016/S0161-6420(98)91568-8

[21] Koch, D.D. and Kohnen, T. (1997) Retrospective Comparison of Techniques to Prevent Secondary Cataract Formation after Posterior Chamber Intraocular Lens Implantation in Infants and Children. Journal of Cataract \& Refractive Surgery, 23, 657-663. https://doi.org/10.1016/S0886-3350(97)80050-8

[22] BenEzra, D. and Cohen, E. (1997) Posterior Capsulectomy in Pediatric Cataract Surgery: The Necessity of a Choice. Ophthalmology, 104, 2168-2174. https://doi.org/10.1016/S0161-6420(97)30045-1

[23] Knight-Nanan, D., O’Keefe, M. and Bowell, R. (1996) Outcome and Complications of Intraocular Lenses in Children with Cataract. Journal of Cataract \& Refractive Surgery, 22, 730-736. https://doi.org/10.1016/S0886-3350(96)80312-9

[24] Malukiewicz-Wisniewska, G., Kaluzny, J., Lesiewska-Junk, H. and Eliks, I. (1999) Intraocular Lens Implantation in Children and Youth. Journal of Pediatric Ophthalmology \& Strabismus, 36, 129-133.

[25] Stager Jr., D.R., Weakley Jr., D.R. and Hunter, J.S. (2002) Long-Term Rates of PCO Following Small Incision Foldable Acrylic Intraocular Lens Implantation in Children. Journal of Pediatric Ophthalmology \& Strabismus, 3, 73-76.

[26] Gimbel, H.V., Basti, S., Ferensowicz, M. and DeBroff, B.M. (1997) Results of Bilateral Cataract Extraction with Posterior Chamber Intraocular Lens Implantation in Children. Ophthalmology, 104, 1737-1743. https://doi.org/10.1016/S0161-6420(97)30033-5

[27] Stager, D., Wang, X., Weakly Jr., D.R. and Felius, J. (2006) The Effectiveness of Nd: YAG Laser Capsulotomy for the Treatment of Posterior Capsule Opacification in Children with Acrylic Intraocular Lenses. Journal of American Association for Pediatric Ophthalmology and Strabismus, 10, 159-163.

https://doi.org/10.1016/j.jaapos.2005.10.003 